\title{
People's Motivation to Participate in Social Network Sites, Subsequent Behaviours, and Situation Self-Awareness following a Crisis: Evidence from the MH370 Flight Incident
}

\author{
Xuequn Wang \\ Murdoch University \\ xuequnwang1600@gmail.com
}

\section{Abstract}

As peopleincreasingly integrate social network sites (SNSs) into their daily lives, they also turn to these sites for timely information following crises. To date, few studies have examined the effects of different types of motivation on participatory behaviours within SNSs following crises. In this study, self-determination theory (SDT) is applied to examine howindividuals are motivated to participate in SNSs following a crisis and how individuals' participatory behaviours can better assist them understand a crisis. The Malaysia Airlines Flight 370 (MH370) incident is selected as the context for this study, and data is collected following the incident. The results show that different types of motivation result in different participatory behaviours. Controlled motivation is positively related to browsing content, commenting and sharing content. Conversely, autonomous motivation is positively associated with browsing and sharing content. Besides, browsing content and commenting are positively related to people's situational self-awareness. The theoretical and practical implications of this study are discussed.

Keywords: Social network sites; participatory behaviours; motivation; situational selfawareness; crisis; MH370.

\section{Introduction}

As people increasingly integrate social network sites (SNSs) into their daily life, they also turn to SNSs following crises (Shklovski et al., 2008; Vieweg et al., 2008). SNSs can increase the resilience of affected individuals (Wang and Li, In Press) and enablethe public to obtain timely information about a crisis (Pang and Ng, In Press). For example, in the 2007 Southern California wildfires, residents used blogs and other information and communication technologies (ICTs) to acquire valuable local information (e.g., whether to evacuate) (Shklovski et al., 2008). During the 2013 Little India Riot, the public used Twitter to access timely information and ascertain responses to the crisis (Pang and Ng, In Press). Spence et al. (2015) argue that individuals who use SNSs regularly in their daily lives probably turn to these sites for information in a crisis.

Despite the importance of SNSs during or following crises, several gaps remain in the literature. First, few studies have examined how the public participates in SNSs following crises (Pan et al., 2012). Recent studies have begun to examine how the public uses SNSs to responds to crises over time (Pang and Ng, In Press; Spence et al., 2015). However, little is known about how individuals are motivated to participate in SNSs to seek relevant information with different approaches. Some may browse SNSs and comment on crisis-related content, while others may also share content within their social networks. Thus, an important question arises: How are people motivated to participate in SNSs differently following crises?

Further, little is known about how different participatory behaviours in SNSs assist the public to understand crises. Specifically, individuals may browse the crisis-related content posted by others, comment on others' content, or share certain content within SNSs; so the question arises: How do these different participatory behaviours assist people to understand crises? 
To answer these two questions and address gaps in the existing literature, this study selects the Malaysia Airlines Flight 370 (MH370) incident as the context. Specifically, this study examines how people's different types of motivation within SNSs result in various participatory behaviours following the MH370 incident and how those participatory behaviours help individuals better understand the crisis. This study applies self-determination theory (SDT) to examine how different types of motivation lead to different participatory behaviours on SNSs. According to SDT, people are motivated to engage in behaviours either to obtain external rewards or because they integrate the rationale of the activities into their own values (Ryan and Deci, 2000). Thus, SDT can provide valuable insights into why people are motivated to participate differently.

This study has three main objectives. First, it seeks to examine how different types of motivation can result in different participatory behaviours within SNSs following a crisis. Extending upon earlier research, this study examines browsing content, commenting and sharing content behaviours and how different types of motivation support those behaviours. The results can contribute to the literature by informing the reasons why people participate differently on SNSs following a crisis.

The second objective is to assess how different social factors support different types of motivation. As different types of motivation may lead to different participatory behaviours, practitioners (such as emergency managers) may be interested in understanding how different types of motivation could be supported. According to SDT, people's motivation can be controlled or autonomous. With controlled motivation, individuals tend to act for external reasons (e.g., monetary rewards) or internal pressures. Conversely, autonomously motivated individuals are more likely to act because they integrate behavioural values with their own values (e.g., individuals may exercise for good health). Such individuals understand the rationale of their behaviours. Thus, this study assesses how social influence leads to controlled motivation and how trust can support autonomous motivation

The effect of social influence on controlled motivation is examined, as people tend to engage in certain activities valued by their significant others (Ryan and Deci, 2000). For example, people may participate in a certain SNS, even if they do not integrate participating in the SNS into their own values, simply because their friends or relatives participate in the same SNS (Boyd and Ellison, 2007). In such a scenario, people act out of controlled motivation. Thus, the effect of social influence on controlled motivation should be examined.

The role of trust on autonomous motivation is also examined. Recent research has shown that trust can enhance people's psychological needs (Wang and Li, 2014), which in turn can support their autonomous motivation (Ryan and Deci, 2000). Thus, this study examines whether trust beliefs toward others directly enhance people's autonomous motivation. By arguing that different types of motivation are supported by different social factors, our study can contribute to the literature by providing a deeper theoretical understanding of motivation and enable useful guidelines to be formulated that promote different types of motivation.

Finally, this study seeks to examine the effects of participatory behaviours. Specifically, we argue that the public could obtain a better understanding of the crisis by participating in SNSs. This study introduces the concept of situational self-awareness to represent people's understanding of a crisis and examines how people's participatory behaviours enhance their situational self-awareness. Here situational self-awareness refers to the consciousness of an individual's internal state (e.g., thoughts and feelings) and surroundings (Buss, 1980). Thus, this study makes a significant contribution to the literature by determining how the public understands crises through various participatory behaviours.

The rest of the paper is organized as follows: We first review the literature on crises and outlines various participatory behaviours in SNSs. Then the theoretical foundation of the study is discussed and the hypotheses are developed. Next, the data collected following the MH370 incident are discussed and the results of data analysis are presented. Finally, the theoretical and practical implications of the study are discussed. 


\section{Literature Review}

\subsection{Crises}

Crises refer to non-routine events that usually involve social disruption (Fritz, 1961). Examples of crises include natural disasters (e.g., earthquakes, floods) and human-made disasters (e.g., terrorist attacks, aircraft crashes). In addition to traditional media such as newspapers and television, SNSs have recently emerged as another important source of crisis-related information. Previous studies have shown that information seeking is one of the main reasons individuals participate in SNSs (Park et al., 2009; Raacke and Bonds-Raacke, 2008). SNSs are more interactive and dialogic (Schultz et al. 2011) than traditional forms of media, can reach a larger audience, and allow audience members to interact with one another. Thus, SNSs can provide a higher level of participation, openness, conversation, and connectedness (Mayfield, 2006) and more timely information.

Recent literature has recognized theimportance of SNSs for both natural disasters and humanmade disasters (e.g., Palen et al., 2009; Shklovski et al. 2010; Starbird and Palen, 2010; Taylor et al., 2012; Yanay et al., 2011). For example, in relation to natural disasters, SNSs have been used to find missing people and offer various types of help such as offering food, water, and shelters following the 2005 Hurricane Katrina (Palen et al., 2007). During the 2007 Southern California wildfires, SNSs were used to distribute community-relevant information as to the areas affected by wildfires and evacuation warnings (Shklovski et al., 2008). In the 2010 Haiti Earthquake, SNSs were used to offer needed medication (Sarcevic et al., 2012).

In relation to human-made disasters, SNSs were used to list victims of the 2007 Virginia Tech Shooting (Vieweg et al., 2008). SNSs also allowed people to voice dissent against institutionalized power during the 2011 Egyptian Uprising (Al-Ani et al., 2012). Further, following the Second Gulf War, SNSs were used to build resilience and pursue daily routines (e.g., going to work or school, traveling, and contacting relatives and friends) (Wang and $\mathrm{Li}$, In Press).These studies show how SNSs can help affected people respond to and recover from crises.

Crises can cause the public to feel a high degree of uncertainty and anxiety (Mitroff, 2004). In many instances, the public may be distant to the sites of crises and crises may damage telecommunication infrastructures (e.g., landline telephones and power stations have been destroyed in crises) (Semaan and Mark, 2011) resulting in information about crises not being broadcast. Further, accurate information about crises may be difficult to obtain (Hagar and Haythornthwaite, 2005) even if the public wants to know more (Boyle et al., 2004; Procopio and Procopio, 2007). Accordingly, in addition to those directly affected by crises, the public also wants timely and relevant information about crises.

However, few studies have examined how the public has used SNSs to gather timely and relevant information about crises (Spence et al., 2015). One exception is from Pang and $\mathrm{Ng}$ (In Press), who examine how the public uses Twitter to respond to the 2013 Little India Riot. Timely and relevant information can help the public better understand a crisis. This understanding can facilitate the public engaging in remedial activities (Chen et al., 2007; Spence et al., 2006) (e.g., donating money, clothes or other supplies to areas severely damaged by natural disasters) (Pan et al., 2012)). The public may also become "digital volunteers" to help those affected by crises (e.g., to help translate information and move information between sources) (Starbird and Palen, 2011). In such circumstances, SNSs can be used to update the public with timely information in relation to the crisis and provide platforms where people can show their support to affected individuals (Ahmed and Sinnappan, 2013). Thus, providing crisis-related information via SNSs can fulfil the public's need for information in relation to the crisis, rescue efforts, government responses, and the assistance being provided (Spence et al. 2015). On the other hand, few studies have differentiated people's participatory behaviours within SNSs after crises.

In summary, the importance of SNSs in distributing crisis-related information has been recognized in the literature; however, previous literature has mainly examined SNS messages 
related to crises, and few studies have examined how the public obtains timely information through SNSs to better understand crises (Pan et al., 2012; Pang and Ng, In Press). This study examines how different participatory behaviours within SNSs can help people better understand a crisis. Because people can have different participatory behaviours in SNSs, below we clarify how people's various participatory behaviours differ.

\subsection{Participatory Behaviours in SNSs}

SNSs are defined as "web-based services that allowindividuals to (1) construct a public or semipublic profile within a bounded system, (2) articulatea list of other users with whom they share a connection, and (3) view and traverse their list of connections and those made by others within the system" (Boyd and Ellison, 2008, p. 211). On SNSs, people can post new content, browse, comment on or share the content of others (Boyd and Ellison, 2008).

Different participatory behaviours above can require different levels of cognitive effort (Wang, 2014). Notably, although browsing content forms the foundation of many other behaviours, it requires relatively less effort and is more popular than other behaviours (Benevenuto et al., 2009). Commenting on content (Wang, 2014) or sharing content requires slightly more effort, but remains cognitively easy. Lastly, posting new content is more difficult and requires more effort and engagement (Wang, 2014). This study focuses on browsing, commenting on and sharing content, as these behaviours are important mechanisms for exchanging information on SNSs (Oh et al., 2013).

It is important to clarify that different levels of cognitive effort are required for different participatory behaviours because people may participate in SNSs with different motivations (Park et al., 2009; Raacke and Bonds-Raacke, 2008). For example, when individuals are motivated by external rewards, they likely focus on how to maximize their rewards and minimize their efforts (Ryan and Deci, 2000). Such individuals are likely to engage in participatory behaviours that require relatively little effort such as commenting (Wang, 2014). Conversely, when individuals are motivated by entertainment, they likely enjoy interacting with others on SNSs and thus spend more time and expend more effort on SNSs. Accordingly, various behaviours are likely supported by different types of motivation.

\section{Theoretical Background and Hypotheses Development}

SDT is applied as the theoretical foundation for this study. SDT differentiates between various types of motivation and clarifies social factors supporting different types of motivation (Ryan and Deci, 2000). SDT can thus be useful to examine the supporting conditions and outcomes of different types of motivation.

\subsection{Self-Determination Theory (SDT)}

SDT identifies intrinsic motivation and four types of extrinsic motivation (external regulation, introjected regulation, identified regulation, and integrated regulation). Different types of extrinsic motivation have different levels of self-determination and can be divided into autonomous motivation (e.g., identified regulation or integrated regulation) and controlled motivation (e.g., external regulation or introjected regulation) (Gagne and Deci, 2005; Reinholt et al., 2011). ${ }^{1}$

The distinction between autonomous motivation and controlled motivation is important because it implies that motivation not only differ quantitatively (i.e., the amount of motivation), but also qualitatively (i.e., the underlying goals or reasons) (Ryan and Deci, 2000). In the context of SNSs, individuals with controlled motivation may participate to obtain the external rewards that some SNSs use to encourage participatory behaviours and rank their users. For example, Weibo.com, a Chinese SNS similar to Twitter, provides medals to

\footnotetext{
${ }^{1}$ Intrinsic motivation is also autonomy-oriented. This study only focuses on people's extrinsic motivations.
} 
encourage participatory behaviours and rank users. ${ }^{2}$ With higher rankings, people obtain higher statuses and more privileges (e.g., they can search for others with the same or similar interests). Thus, users of weibo.com with controlled motivation primarily focus on how to achieve higher rankings. Conversely, users with autonomous motivation may participate because they enjoy communicating and interacting on SNSs and integrate those behaviours into their own values (Wang, 2014). These users are likely to place less value on external rewards. In these two contexts, individuals may have the same levels of motivation, but different orientations.

Autonomous motivation takes time to develop and maintain (Ryan and Deci, 2000); however, crises usually only last for short periods. Accordingly, it is more appropriate to examine how people's general motivation in relation to SNSs influences their subsequent participatory behaviours within SNSs following a crisis (Wang, 2014). Spence et al. (2015) also suggest that people's daily patterns of use and gratification processes within SNSs might influence their behaviours within SNSs during a crisis. The next section sets out the hypotheses developed based on SDT and other relevant research.

\subsection{Social Influence and Controlled Motivation}

Social influence is defined as "the degree to which an individual perceives that important others believe he or she should use the new system" (Venkatesh et al., 2003, p. 451). Social influence can affect individuals' behaviours through three mechanisms: compliance, internalization, and identification (Venkatesh and Davis, 2000). This study focuses on the compliance mechanism to exclude the effect of a supportive environment (Thompsonet al., 1991). The compliance mechanism alters individuals' motivations in response to social pressure without changing their belief structures (Venkatesh et al., 2003). Thus, in relation to social influence, individuals may be motivated to perform a behaviour without holding a positive attitude toward the behaviour if they perceive that important social actors wish them to engage in the behaviour (Warshaw, 1980). In the context of SNSs, if individuals' important friends, classmates, or workmates want them to participate in specific SNSs and value high rankings within those SNSs, individuals may engage in the necessary behaviours to try to achieve higher rankings within those SNSs. By participating in those SNSs and achieving high rankings, individuals may feel that their images are enhanced (Moore and Benbasat, 1991). In such a context, individuals are motivated to participate to obtain higher rankings valued by others, but they may not integrate participation into their belief structures. Thus, it is hypothesized that:

H1: Social influence (compliance) is positively related to controlled motivation in SNSs.

\subsection{Trust and Autonomous Motivation}

Three types of trust beliefs have been identified: benevolence, competence, and integrity (Bhattacherjee, 2002; McKnight et al., 2002). Here competence trust beliefs refer to individuals' perception of others' knowledge in a certain area (Bhattacherjee, 2002). This study examines how people's trust toward others can support their autonomous motivation within SNSs. Since people generally join SNSs to interact with others rather than to complete predefined tasks (e.g., finish business transactions), competence trust beliefs are not relevant to this study. Accordingly, this study focuses on the trust beliefs of benevolence and integrity to determine people's perceptions toward others.

Benevolence trust beliefs refer to trustees' acting in trusters' interests (McKnight et al. 2002) and can be used to determine whether trustees' intentions are based on altruism (Mayer et al. 1995). In the context of SNSs, benevolence trust beliefs between participants could reveal whether individuals perceive others as caring about their interests or how others show their willingness to assist in relation to specific needs. For example, if individuals post questions about a crisis on SNSs, others may attempt to answer these questions, resulting in a higher level of benevolence trust beliefs toward other participants. In this circumstance, individuals

2 http:// help.weibo.com/ faq/ q/ 358 
that make the posts are more likely to feel supported by others, which in turn support their autonomous motivation (Ryan and Deci, 2000).

Integrity trust beliefs refer to the degree to which trustees will adhere to a set of rules of interaction acceptable to trusters (McKnight et al. 2001). Integrity trust reflects whether trustees keep their promises and behave reliably (McKnight et al. 2002). Rules of integrity for participants within SNSs can include producing various types of content and friendly interactions among users. Thus, integrity trust beliefs are used to refer to the degree to which other participants are friendly and keep their commitments. When individuals perceive that others are truthful in their SNS interactions, their integrity trust beliefs are likely to increase. Consequently, such individuals may feel that they can reliably participate in SNSs in the future and their autonomous motivation is thus supported (Ryan and Deci, 2000). Previous literature has shown that integrity trust beliefs can enhance people's willingness to engage in online transactions (Bhattacherjee, 2002). To summarize, we argue that:

H2a: Benevolence trust beliefs are positively related to autonomous motivation in SNSs.

H2b: Integrity trust beliefs are positively related to autonomous motivation in SNSs.

\subsection{Controlled Motivation and Participatory Behaviours}

Previous SDT studies have shown that autonomous and controlled motivation may lead to different task outcomes (Gagne and Deci, 2005; Wang, 2014). Controlled motivation, such as external rewards, often leads to mundane and simple tasks (Amabile et al., 1990; McGraw, 1978; McGraw and McCullers, 1979). For example, in the context of Information Technology (IT) support, Wang et al. (2015) find that external motivation, a specific type of controlled motivation, is positively related to mundane knowledge contribution (i.e., knowledge contribution via documents). In the context of SNSs, individuals with controlled motivation are likely to focus on external rewards (e.g., medals, high rankings) and tend to minimize their cognitive efforts whenever possible. Thus, they may select easier participatory behaviours, such as commenting and sharing content. Commenting is a simple task that requires relatively little cognitive effort, as people can comment on already created content by adding a few words (Starbird and Palen, 2012). Sharing content is also an easy task; content can be shared just by clicking a "Share" button.

Following a crisis, people with controlled motivations need timely information about the crisis (Boyle et al., 2004) and tend to minimize the cognitive effort they expend during the process. Consequently, they are more likely to comment or share content (Starbird and Palen, 2012) to maximize their rewards. Wang (2014) also find that people's controlled motivation is positively related to commenting on SNSs following a crisis. Before commenting, people need to browse the content, at least cursorily, to ensure their comment makes sense. Therefore, we hypothesize that:

H3a: Controlled motivation is positively related to browsing content on SNSs.

H3b: Controlled motivation is positively related to commenting on SNSs.

H3c: Controlled motivation is positively related to sharing content on SNSs.

\subsection{Autonomous Motivation and Participatory Behaviours}

Autonomous motivation often leads to people seeking out complex and challenging tasks (McGraw, 1978; Vansteenkiste et al., 2004), but may not influence simple or mundane tasks (Gagneand Deci, 2005). Individuals with high levels of autonomous motivation do not engage in behaviours for external rewards, but act because they understand the rationale of those activities and integrate those activities into their own values (Ryan and Deci, 2000). For example, Wang et al. (2015) find that the intrinsic motivation of system administrators is positively related to challenging knowledge contribution (i.e., knowledge contribution via tickets).

Following a crisis, individuals with autonomous motivation understand that they need to facilitate the distribution of crisis-related information within SNSs to ensure that others have 
access to the information. These individuals may not wish to exert much effort in commenting (Wang, 2014), as commenting is neither challenging nor helpful in distributing the information. Conversely, sharing content can help distribute the information and inform more people about the crisis. Thus, these individuals will probably engage in content sharing. Again, before sharing content, theseindividuals need to browse the content to learn more about crises (Boyle et al. 2004; Procopio and Procopio, 2007) and ensure that the information is relevant to others. Thus, it was hypothesized that:

H4a: Autonomous motivation is positively related to browsing content on SNSs.

H4b: Autonomous motivation is negatively related to commenting on SNSs.

H4c: Autonomous motivation is positively related to sharing content on SNSs.

\subsection{Participatory behaviours and Situational Self-Awareness}

Situational self-awareness includes three sub-dimensions: private self-awareness, public selfawareness, and awareness of immediate surroundings (Govern and Marsch, 2001). Public selfawareness includes paying attention to the features presented to the public (e.g., physical features); private self-awareness includes being attentive to internal, personal aspects (e.g., feelings of physical pleasure) (Buss, 1980).These two dimensions reflect people's self-focus; thus, they do not assist in examining how people understand their environment following a crisis.

This study focuses on the third dimension-awareness of immediate surroundings; that is, the situation that arises when an individual's attention is focused on something other than themselves. Situational self-awareness can be helpful to reveal how people understand what is happening in relation a specific crisis. Following a crisis, people seek up-to-date, relevant information about the crisis (Boyle et al., 2004; Procopio and Procopio, 2007). By browsing, commenting on or sharing crisis-related content within SNSs, people can better understand the crisis and what is occurring, which in turn should lead to a higher level of situational selfawareness. Thus, it is hypnotized that:

H5a: Browsing content on SNSs is positively related to situational self-awareness.

H5b: Commenting on SNSs is positively related to situational self-awareness.

H5c: Sharing content on SNSs is positively related to situational self-awareness.

As discussed above, people with various types of motivation may participate differently in SNSs following a crisis. Specifically, people may share crisis-related content within SNSs for different reasons (i.e., with different types of motivation). People with controlled motivation may share content to gain external rewards, while those with autonomous motivation may share content to facilitate information sharing. Therefore, the effect of sharing content on situational self-awareness may be different in different scenarios. People with controlled motivation may simply increase the frequency of sharing the crisis-related content to maximize rewards without carefully browsing each piece of content; thus, such sharing may not assist them to better understand the crisis. Conversely, people with autonomous motivations may carefully select and share certain content to help others better understand the crisis; thus, sharing that content can help them better understand the crisis. To summarize, we hypothesize that:

H6: Motivation and sharing content on SNSs will interact such that: (a) content sharing on SNSs by people with controlled motivations is not significantly related to situational selfawareness; (b) content sharing on SNSs by people with autonomous motivation is significantly related to situational self-awareness.

Our research model is presented in Figure 1. 


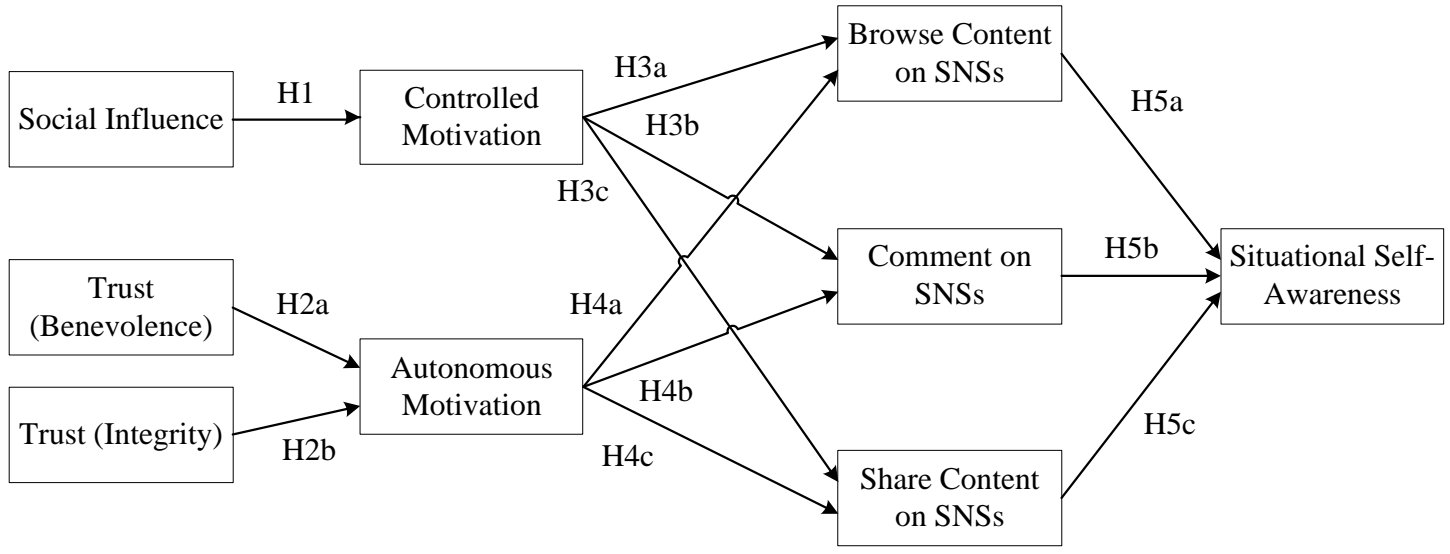

Figure 1. Research Model

\section{Method}

This section describes the context, sample, measures, data analysis, and the results of the study.

\subsection{Context}

The MH370 incident was selected as the context for this study. MH370 was a flight scheduled to fly internationally from Kuala Lumpur, Malaysia to Beijing, China on March 8, 2014 ${ }^{3}$. After less than one hour in the air, it lost contact with air traffic control and disappeared at 01:20 MYT. It was not until later that night that Malaysia Airlines reported the flight missing. A multinational search effort then started in the Gulf of Thailand and the South China Sea and soon extended to the Strait of Malacca and Andaman Sea. Later, the focus of the search turned to the southern part of the Indian Ocean. No confirmed flight debris was found or crash site identified. Consequently, unofficial news items were published and rumours spread about the MH370 incident and people began continuously searching for news updates from various sources. This makes the MH370 incident an appropriate context to examine how the public participates on SNSs to learn more about crises.

Data was collected between March 24 and April 6 in 2014. These dates were selected as by this period, participants had already participated in SNSs in some way to learn more about the incident and might not have turned to other events or incidents. Of the 227 passengers on the MH370 flight, 152 were Chinese citizens. Thus, the Chinese public was particularly eager to learn more about the incident and was selected to participate in this study.

\subsection{Sample}

Participants came from two sources. More than half of the participants (i.e. 64 percent, $n=$ 130) were junior level business students at a large public university in the northeast of China. The remaining participants (i.e., 36 percent, $n=73$ ) were recruited using a snowball procedure (i.e., the student participants were asked to refer non-student friends or relatives who often used SNSs and might be interested in the MH370 incident). Screening questions were added to remove those who either did not use SNSs regularly or had not browsed, commented on or shared content of the MH370 incident on SNSs. Approximately one percent course credit was awarded to students for participating and referring additional participants. Table 1 lists the demographic information of the participants. 


\begin{tabular}{|l|l|c|c|}
\hline & Category & $\begin{array}{c}\text { Student Sample } \\
(\mathbf{n}=\mathbf{~ 1 3 0 )}\end{array}$ & $\begin{array}{c}\text { "Snowball" Sample } \\
(\mathbf{n}=\mathbf{7 3})\end{array}$ \\
\hline \multirow{2}{*}{ Gender } & Female & $81(62.3 \%)$ & $47(64.4 \%)$ \\
\cline { 2 - 4 } & Male & $49(37.7 \%)$ & $26(35.6 \%)$ \\
\hline Age & & $21.6(\mathrm{SD} 1.2)$ & $34.9(\mathrm{SD} 10.2)$ \\
\hline \multirow{3}{*}{ SNS used } & Renren & $5(3.8 \%)$ & $7(9.6 \%)$ \\
\cline { 2 - 4 } & WeChat & $100(76.9 \%)$ & $41(56.2 \%)$ \\
\cline { 2 - 4 } & Weibo & $22(16.9 \%)$ & $16(21.9 \%)$ \\
\cline { 2 - 4 } & Other & $3(2.3 \%)$ & $9(12.3 \%)$ \\
\hline Tenure (years) & & $2.5(\mathrm{SD} 1.1)$ & $2.4(\mathrm{SD} 1.9)$ \\
\hline
\end{tabular}

Table 1. Sample Demographic Information

Snowball sampling is an appropriate mode of data collection for this study. This method has been found to be effective in locating, accessing, and involving hard-to-reach populations (Cohen and Arieli, 2011; Valdez and Kaplan, 1999). The target population of this study is those who browsed, commented on, or shared content related to the MH370 incident in SNSs. As not everyone is interested in the MH370 incident, it is challenging to locate members of this population. Thus, snowball sampling is suitable for this study.

Admittedly, representativity can be an issue of snowball sampling (Cohen and Arieli, 2011). Thus, the age groups of participants and the industries they worked in were closely examined. The sample covered a variety of age groups and industries (see Table 2). Thus, the sample had an acceptable level of representativity across the whole population of SNS users. ${ }^{4}$

\begin{tabular}{|l|l|c|}
\hline \multirow{4}{*}{ Age } & \multicolumn{1}{|c|}{ Category } & Sample \\
\hline \multirow{5}{*}{ Industry } & Below 29 & $81.28 \%$ \\
\cline { 2 - 3 } & $30-39$ & $3.45 \%$ \\
\cline { 2 - 3 } & $40-49$ & $13.79 \%$ \\
\cline { 2 - 3 } & Above 50 & $1.48 \%$ \\
\cline { 2 - 3 } & Student & $48.77 \%$ \\
\cline { 2 - 3 } & Banking/ Finance & $11.82 \%$ \\
\cline { 2 - 3 } & Education (K- 12) & $3.94 \%$ \\
\cline { 2 - 3 } & Government & $7.39 \%$ \\
\cline { 2 - 3 } & Higher education & $1.97 \%$ \\
\cline { 2 - 3 } & Hospitality & $0.49 \%$ \\
\cline { 2 - 3 } & Manufacturing & $4.43 \%$ \\
\cline { 2 - 3 } & Transportation & $1.48 \%$ \\
\cline { 2 - 3 } & Health care & $2.96 \%$ \\
\cline { 2 - 3 } & Other & $16.75 \%$ \\
\hline
\end{tabular}

Table 2. Sample's Age and Industry

\subsection{Measures}

Items of our study were adapted from the literature. Specifically, items for controlled motivation, autonomous motivation, browsing content, sharing content, and commenting on SNSs were adapted from Ke and Zhang (2010). Items for social influence were adapted from Moore and Benbasat (1991) and Taylor and Todd (1995); items for trust were adapted from McKnight et al. (2002); items for situational self-awareness were adapted from Govern and Marsch (2001). Each question was measured on a 7-point, Likert-type scale, where "1" indicated "strongly disagree" and "7" indicated "strongly agree." The final items used are shown in the appendix.

\footnotetext{
${ }^{4}$ http:// www.alibuybuy.com/ posts/ 88202.html
} 


\subsection{Analysis and Results}

Our model was tested using partial least squares (PLS). PLS is appropriate for predictive models and theory building (Barclay et al., 1995; Chin, 2010). SmartPLS (Ringle et al., 2005) was used in the analysis, and the bootstrap re-sampling method (using 5000 samples) was used to determine the significance of the paths in the structural model. PLS is preferred as the analytical technique for this study for several reasons. First, as few similar studies have been conducted, this study is exploratory in nature and PLS is preferred over covariance-based statistical tools in exploratory studies (Gefen et al., 2011). Second, PLS works well with smallto-medium sized samples (Chin, 2010). Third, the model tested in this study predicts people's situational self-awareness and PLS is suited to predictive models (Chin, 2010).

First, common method variance (CMV) was examined (Lindell and Whitney, 2001; Podsakoff et al. 2003). An exploratory factor analysis of all items showed that six factors explained 71.01 percent of the variance, with no single factor accounting for significant loading (at the $p<.10$ level) for any item. The second-smallest positive correlation among the manifest variables was then used as a conservative estimate of CMV (Lindell and Whitney, 2001). Following adjustment, all the significant correlations remained significant. Thus, CMV was probably not an issue in this study.

Next, data analysis was conducted in two stages: measurement model and structural model assessment. In the first stage, convergent validity was confirmed if it met the following criteria (Gefen and Straub, 2005): (i) each item loaded significantly on its respective construct and none of the loadings were below the cut-off value of 0.60 (see Table 3); (ii) the composite reliabilities (CRs) of all constructs were above 0.70 (see Table 3); and (iii) the average variance extracted (AVE) from all constructs was above the threshold value of 0.50 (Tables 3).

\begin{tabular}{|c|c|c|c|c|c|}
\hline Items & Mean & S.D. & Loadings & AVE & CR \\
\hline SI1 & 5.49 & 1.15 & 0.70 & \multirow{4}{*}{0.61} & \multirow{4}{*}{0.86} \\
\hline SI2 & 5.50 & 1.20 & 0.75 & & \\
\hline SI3 & 3.97 & 1.54 & 0.83 & & \\
\hline SI4 & 4.17 & 1.43 & 0.83 & & \\
\hline TB1 & 4.34 & 1.36 & 0.73 & \multirow{4}{*}{0.70} & \multirow{4}{*}{0.90} \\
\hline TB2 & 4.97 & 1.22 & 0.89 & & \\
\hline TB3 & 4.67 & 1.22 & 0.84 & & \\
\hline TB4 & 4.76 & 1.11 & 0.87 & & \\
\hline TI1 & 4.85 & 1.16 & 0.89 & \multirow{4}{*}{0.85} & \multirow{4}{*}{0.96} \\
\hline TI2 & 4.56 & 1.21 & 0.94 & & \\
\hline TI3 & 4.52 & 1.15 & 0.93 & & \\
\hline T14 & 4.68 & 1.14 & 0.93 & & \\
\hline CM1 & 5.03 & 1.30 & 0.66 & \multirow{3}{*}{0.61} & \multirow{3}{*}{0.82} \\
\hline CM2 & 4.49 & 1.47 & 0.88 & & \\
\hline CM3 & 4.84 & 1.35 & 0.79 & & \\
\hline AM1 & 5.57 & 0.96 & 0.83 & \multirow{3}{*}{0.66} & \multirow{3}{*}{0.86} \\
\hline AM2 & 5.33 & 1.28 & 0.85 & & \\
\hline AM3 & 4.94 & 1.24 & 0.76 & & \\
\hline VSNS1 & 5.31 & 1.43 & 0.98 & \multirow{2}{*}{0.97} & \multirow{2}{*}{0.98} \\
\hline VSNS2 & 5.18 & 1.49 & 0.98 & & \\
\hline FSNS1 & 4.27 & 1.71 & 0.96 & \multirow{2}{*}{0.92} & \multirow{2}{*}{0.96} \\
\hline FSNS2 & 4.13 & 1.76 & 0.96 & & \\
\hline CSNS1 & 3.83 & 1.77 & 0.97 & \multirow{2}{*}{0.95} & \multirow{2}{*}{0.97} \\
\hline CSNS2 & 3.88 & 1.72 & 0.98 & & \\
\hline SA1 & 5.29 & 1.35 & 0.86 & \multirow{3}{*}{0.81} & \multirow{3}{*}{0.93} \\
\hline SA2 & 5.33 & 1.15 & 0.92 & & \\
\hline SA3 & 5.34 & 1.11 & 0.93 & & \\
\hline
\end{tabular}

Table 3. Items and Descriptive Statistics 
Discriminant validity was established by ensuring that the square root of AVE for each construct exceeded all the correlations between that construct and any other construct (Gefen and Straub, 2005) (see Table 4). Overall, the measures demonstrated good psychometric properties.

\begin{tabular}{llllllllll}
\hline & 1 & 2 & 3 & 4 & 5 & 6 & 7 & 8 & 9 \\
\hline 1 Social Influence & $\mathbf{0 . 7 8}$ & & & & & & & & \\
2 Trust (Benevolence) & 0.57 & $\mathbf{0 . 8 4}$ & & & & & & & \\
3 Trust (Integrity) & 0.46 & 0.71 & $\mathbf{0 . 9 2}$ & & & & & & \\
4 Controlled Motivation & 0.49 & 0.52 & 0.38 & $\mathbf{0 . 7 8}$ & & & & & \\
5 Autonomous Motivation & 0.51 & 0.62 & 0.54 & 0.59 & $\mathbf{0 . 8 1}$ & & & & \\
6 Browse Content in SNSs & 0.32 & 0.34 & 0.24 & 0.42 & 0.42 & $\mathbf{0 . 9 8}$ & & & \\
7 Share Content in SNSs & 0.29 & 0.33 & 0.13 & 0.35 & 0.35 & 0.56 & $\mathbf{0 . 9 6}$ & & \\
8 Comment in SNSs & 0.34 & 0.36 & 0.21 & 0.34 & 0.28 & 0.44 & 0.70 & $\mathbf{0 . 9 7}$ & \\
9 Situational Self-Awareness & 0.26 & 0.34 & 0.19 & 0.38 & 0.40 & 0.54 & 0.37 & 0.35 & $\mathbf{0 . 9 0}$ \\
\hline
\end{tabular}

Table 4. Correlation between Constructs and Square-root of AVEs (on diagonal)

In the second stage, the structural model was assessed using $\mathrm{R}^{2}$ measures and path coefficients. $\mathrm{R}^{2}$ shows the amount of variance in a dependent variable explained by independent variables (Gefen et al., 2000) and path coefficients indicate the significance of the relationships between the constructs.

$\mathrm{H} 1$, stating that social influence is positively associated with controlled motivation, was supported $(\mathrm{b}=0.49, \mathrm{p}<.001)$. H2a argues that benevolence trust beliefs are positively associated with autonomous motivation. This hypothesis was supported $(b=0.48, p<.001)$. $\mathrm{H} 2 \mathrm{~b}$ posits that integrity trust beliefs are positively related to autonomous motivation. This hypothesis was supported $(\mathrm{b}=0.20, \mathrm{p}<.05)$. H3a states that controlled motivation is positively associated with browsing content on SNSs. This hypothesis was supported $(b=0.26$, $\mathrm{p}<.01)$. H3b states that controlled motivation is positively associated with commenting on SNSs. This hypothesis was supported $(b=0.27, \mathrm{p}<.001)$. H3c argues that controlled motivation is positively associated with sharing content on SNSs. This hypothesis was supported $(b=0.23, p<.01)$. H4a states that autonomous motivation is positively associated with browsing content on SNSs. This hypothesis was supported $(b=0.27, p<.01)$. H4b states that autonomous motivation is negatively associated with commenting on SNSs; however, this hypothesis was not supported $(b=0.12, p>.05)$. H4c argues that autonomous motivation is positively associated with sharing content on SNSs. This hypothesis was supported $(b=0.21$, $\mathrm{p}<.01)$. H5a, stating that browsing content is positively associated with situational selfawareness, was supported $(\mathrm{b}=0.48, \mathrm{p}<.001)$. H5b argues that commenting is positively related to situational self-awareness. This hypothesis was supported $(b=0.13, p<.05)$. H5c posits that sharing content is positively related to situational self-awareness; however, this hypothesis was not supported $(b=0.00, p>.05)$. These findings are presented in Figure 2 . 


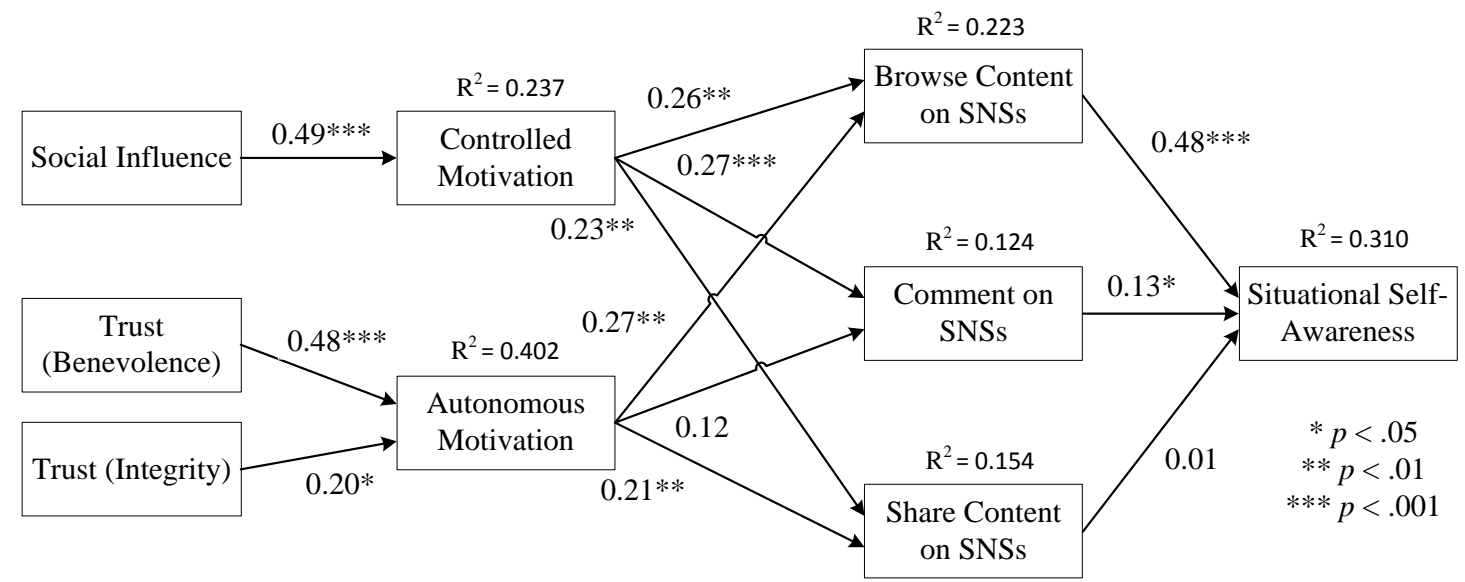

Figure 2. Model Results

The Stone-Geisser $\left(\mathrm{Q}^{2}\right)$ test was then conducted to assess the predictive quality of the model (Geisser, 1975; Stone, 1974). The model has estimation relevance with values of $\mathrm{Q}^{2}$ above 0 . The $\mathrm{Q}^{2}$ for social influence was 0.61; the $\mathrm{Q}^{2}$ for trust (benevolence) was 0.70; the $\mathrm{Q}^{2}$ for trust (integrity) was 0.85 ; the $\mathrm{Q}^{2}$ for controlled motivation was 0.61 ; the $\mathrm{Q}^{2}$ for autonomous motivation was 0.66; the $\mathrm{Q}^{2}$ for browsing content on SNSs was 0.97; the $\mathrm{Q}^{2}$ for commenting on SNSs was 0.95; the $\mathrm{Q}^{2}$ for sharing content on SNSs was 0.92; and the $\mathrm{Q}^{2}$ for situational selfawareness was 0.75 . Thus, the model had good predictive relevance.

\subsection{Moderation Analysis: Motivation, Participatory Behaviours, and Situational Self-Awareness}

To test H6, participants were classified as those with a relatively high level of controlled motivation and those with a relatively high level of autonomous motivation. The process of Koestner and Zuckerman (1994) was followed to classify participants and the z-scores of controlled motivation and autonomous motivation were calculated. A participant was classified as having controlled motivation if his/ her z-score on the controlled motivation scale was higher than his/her z-score of the autonomous motivation scale; otherwise, he/ she was classified as being autonomously motivated. The whole sample was thus divided into two subsamples.

Next, the relationship between sharing content and situational self-awareness was examined for participants with different types of motivation (see Figure 3).The results showed that sharing content was not significantly related to situational self-awareness in participants with controlled motivation, supporting H6a. However, sharing content was only marginally significantly related to situational self-awareness in participants with autonomous motivation. Thus, H6b was marginally supported. 


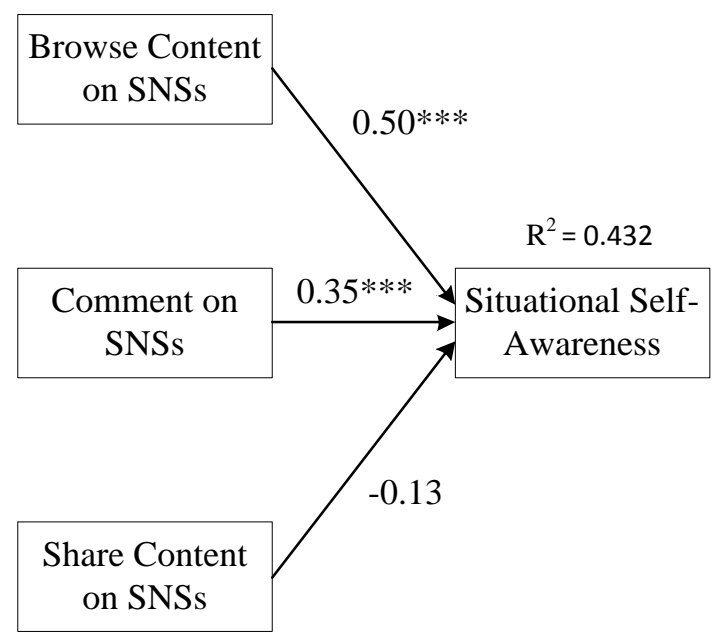

Panel A: Participants with Controlled Motivation ( $n=102)$

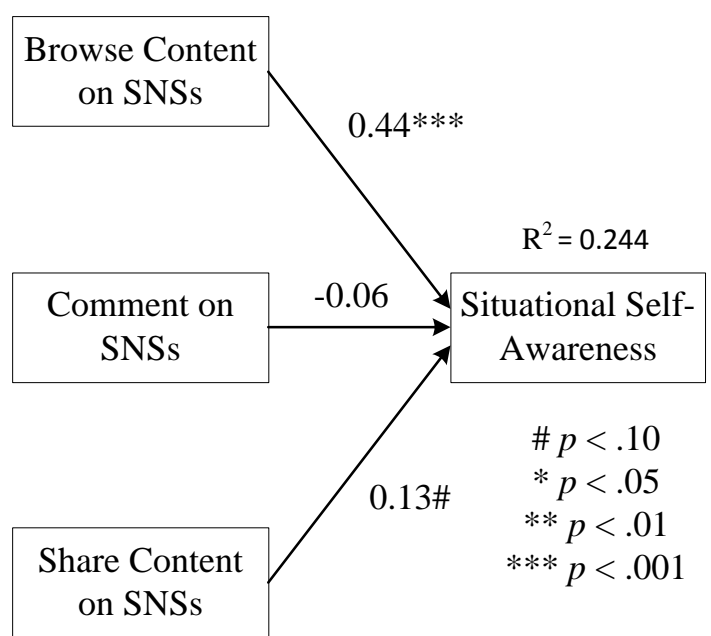

Panel B: Participants with Autonomous Motivation ( $\mathrm{n}=101)$

Figure 3. Participatory behaviours and Situational Self-Awareness for Participants with Different Types of Motivation

\section{Discussion}

This study applies SDT to examine how different social factors support different types of motivation, which in turn result in different participatory behaviours. SDT is also used to examine how participatory behaviours contribute to people's situational self-awareness. Data was collected and analysed following the MH370 incident. The results show that while social influence is positively related to controlled motivation (H1), trust is positively associated with autonomous motivation (H2). Different types of motivation are also found to lead to different participatory behaviours. Controlled motivation is positively related to browsing content, commenting, and sharing content (H3); however, autonomous motivation is only positively associated with browsing and sharing content (H4). Although autonomous motivation is not negatively related to commenting ( $\mathrm{H} 4 \mathrm{~b}$ is rejected), the results still indicate that people with autonomous motivation tend not to comment on others' content.

Overall, it is found that browsing content and commenting are positively related to people's situational self-awareness (H5). Further, the results show that sharing content has a marginal effect on situational self-awareness for people with autonomous motivation, but no effect on those with controlled motivation (H6) (see Table 5). This study has important theoretical and practical implications. 


\begin{tabular}{|c|c|c|}
\hline & $\begin{array}{l}\text { Hypothesis } \\
\end{array}$ & Results \\
\hline H1 & $\begin{array}{l}\text { Social influence (compliance) is positively related to controlled } \\
\text { motivation. }\end{array}$ & Supported \\
\hline $\mathrm{H} 2 \mathrm{a}$ & $\begin{array}{l}\text { Benevolence trust beliefs are positively related to autonomous } \\
\text { motivation. }\end{array}$ & Supported \\
\hline $\mathrm{H} 2 \mathrm{~b}$ & $\begin{array}{l}\text { Integrity trust beliefs are positively related to autonomous } \\
\text { motivation. }\end{array}$ & Supported \\
\hline HЗа & $\begin{array}{l}\text { Controlled motivation is positively related to browsing content on } \\
\text { SNSs. }\end{array}$ & Supported \\
\hline H3b & Controlled motivation is positively related to commenting on SNSs. & Supported \\
\hline H3c & $\begin{array}{l}\text { Controlled motivation is positively related to sharing content on } \\
\text { SNSs. }\end{array}$ & Supported \\
\hline $\mathrm{H} 4 \mathrm{a}$ & $\begin{array}{l}\text { Autonomous motivation is positively related to browsing content on } \\
\text { SNSs. }\end{array}$ & Supported \\
\hline $\mathrm{H} 4 \mathrm{~b}$ & $\begin{array}{l}\text { Autonomous motivation is negatively related to commenting on } \\
\text { SNSs. }\end{array}$ & Rejected \\
\hline $\mathrm{H} 4 \mathrm{c}$ & $\begin{array}{l}\text { Autonomous motivation is positively related to sharing content on } \\
\text { SNSs. }\end{array}$ & Supported \\
\hline H5a & $\begin{array}{l}\text { Browsing content in SNSs is positively related to situational self- } \\
\text { awareness. }\end{array}$ & Supported \\
\hline H5b & $\begin{array}{l}\text { Commenting in SNSs is positively related to situational self- } \\
\text { awareness. }\end{array}$ & Supported \\
\hline $\mathrm{H} 5 \mathrm{c}$ & $\begin{array}{l}\text { Sharing content in SNSs is positively related to situational self- } \\
\text { awareness. }\end{array}$ & Rejected \\
\hline H6 & $\begin{array}{l}\text { Motivation and sharing content on SNSs will interact such that: (a) } \\
\text { content sharing on SNSs by people with controlled motivations is not } \\
\text { significantly related to situational self-awareness; (b) content sharing } \\
\text { on SNSs by people with autonomous motivation is significantly } \\
\text { related to situational self-awareness. }\end{array}$ & $\begin{array}{c}\text { H6a Supported; } \\
\text { H6b Marginally } \\
\text { Supported }\end{array}$ \\
\hline
\end{tabular}

Table 5. Hypotheses Testing Summery

\subsection{Theoretical Implications}

This study makes three important theoretical contributions. First, it shows that different types of motivation lead to different participatory behaviours on SNSs following a crisis. Commenting on and sharing content require relatively little cognitive effort; thus, people with controlled motivation probably browse, comment on and share relevant content on SNSs following the crisis. The significant relationship between controlled motivation and commenting in this study is also consistent with the results of Wang (2014). Conversely, people with autonomous motivation probably understand the rationale for participating in SNSs following a crisis (i.e., to help others understand the crisis better) and integrate this behaviour into their own values. Consequently, they are morelikely to browse and share relevant content. Those results confirm SDT within the context of the MH370 incident. Specifically, SDT argues that people's motivation can be autonomous or controlled, which could lead to various behaviours. Our results show that people's various types of motivation indeed lead to various participatory behaviours. Besides, this study also extends the literature (e.g., Wang, 2014) by examining additional participatory behaviours (i.e., browsing and sharing content) and addresses the gap in the research in relation to how people participate in SNSs to gain information about crises (Pan et al., 2012).

Second, the results show that controlled and autonomous motivation are supported by different social factors. Social influence is positively related to controlled motivation and trust toward other participants is positively associated with autonomous motivation. These results provide valuable insight into how controlled motivation differs from autonomous motivation. Our study also extends previous research (e.g., Wang, 2014; Wang and Li, 2014) by examining the antecedent of controlled motivation and clarifying the role of trust on autonomous motivation. 
Third, our study shows that participatory behaviours can help enhance a person's situational self-awareness and extends previous research (e.g., Wang, 2014) by empirically examining the effects of participatory behaviours. The results show that participatory behaviours are indeed important in the public understanding about a crisis and require further examination.

Besides, participatory behaviours have various effects on people with different types of motivation. Content sharing by those with controlled motivation is not related to situational self-awareness. Thus, people with controlled motivation may simply share content without carefully browsing content to obtain external rewards. Conversely, people with autonomous motivation are not motivated by external rewards, and probably browse the content before sharing. Sharing content is found to have some effect on people with autonomous motivation; however, the effect is only marginally significant. One possible reason is that since people with autonomous motivation are trying to increase others' understanding of a crisis, they may not share content in which they are not confident and thus limiting the frequency of sharing. Clearly, more studies are needed to examine the activity of sharing content following crises.

\subsection{Practical Implications}

This study also has important practical implications. First, it shows that SNSs can help people increase situational self-awareness and make sense of a crisis. Specifically, our results show that overall browsing and commenting on crisis-related content can help people better understand a crisis. These results provide important insights for governments and relevant non-profit organizations as to how the public responds and understands a crisis through SNSs. Thus, people should be encouraged to use SNSs to browse and comment on content related to crises on SNSs, and governments should try to take advantage of SNSs to distribute the crisisrelated information. For example, the government could set up an SNS account and publish verified information that could be browsed and commented upon by SNS users. The information posted could help the public better understand the crisis and plan and coordinate remedial activities. Emergency managers could also be appointed to help the public interpret information in relation to a crisis. Emergency managers need to re-post and update regularly to ensure that the updates appear in searchers related to the crisis (Spence et al., 2015).

Second, the results show that different types of motivation lead to different participatory behaviours, which in turn have different effects on situational self-awareness. These results provide important guidelines to practitioners such as emergency managers. Specifically, emergency managers can use different approaches to enhance people's situational selfawareness and help them better understand a crisis. If people have controlled motivation, simply browsing content and commenting can increase their situational self-awareness. Thus, practitioners should collaborate with operators of SNSs to provide extra rewards to people for commenting on crisis-related content to ensure that people spend more effort browsing content and commenting. When people have autonomous motivation, sharing content has a marginal effect on situational self-awareness. Thus, content sharing should be encouraged and supported. Practitioners can work with operators of SNSs to provide feedback as to how many people have browsed their shared content, and how the shared content benefits them (Wang and Clay, 2012).

Third, our results show that various types of motivation are supported differently. Controlled motivation is enhanced by social influence; autonomous motivation is supported by people's trust toward other participants. These results can help practitioners such as emergency managers better motivate people. For example, emergency managers may want to support different types of motivation at different stages of a crisis. When a crisis has just occurred and people are seeking information about the crisis, both types of motivation should be supported. In this context, emergency managers can support both social influence and trust such that people with different types of motivation share the content and facilitate the distribution of information. However, following a crisis, the government may wish to begin various initiatives to support people's resilience and post information on the initiatives on SNSs. In such a context, controlled motivation should be supported to encourage people to comment on the 
information and provide relevant feedback to the government. Therefore, social influence among people should be supported to increase their controlled motivation.

\subsection{Limitations and Opportunities for Future Studies}

This study has several limitations. First, the MH370 incident is selected as the context for this study. While the results provide valuable insights into the effect of people's participatory behaviours on SNSs following the MH370 incident, these results may not be generalizable to other crises. Future studies are needed to confirm people's SNSs behaviours in other contexts. Second, this study uses snowball sampling to recruit participants from different backgrounds. However, as the sample could be biased, the results must be interpreted cautiously. Future studies could use other methods (e.g., posting a survey link on popular SNSs and in discussion forums related to crises) to assess whether the conclusions reached in this study still hold.

Notwithstanding these limitations, our findings suggest a number of interesting avenues for future research. First, other social factors supporting different types of motivation could be examined. Future studies can also further divide autonomous motivation and controlled motivation and examine how different types of motivation can result in different participatory behaviours. This study focuses on the relationship between people's participatory behaviours and their own situational self-awareness. Future studies could examine how other participants' behaviours help enhance people's situational self-awareness following a crisis.

\section{Conclusion}

This study examines how people's participatory behaviours on SNSs following a crisis are supported by different types of motivation and how participatory behaviours can help people better understand crises. Using data collected following the MH370 incident, our study shows that different types of motivation can result in different participatory behaviours. Further, browsing content and commenting are positively related to people's situational self-awareness. Future studies are needed to extend this research across other contexts and further examine the relationship between motivation and participatory behaviours.

\section{References}

Ahmed, A., \& Sinnappan, S. (2013). "The role of Social media during Queensland floods: An Empirical Investigation on the Existence of Multiple Communities of Practice (MCoPs)," Pacific Asia J ournal of the Association for Information Systems, 5(2): 1-22.

Al-Ani, B., Mark, G., Chung, J ., \& J ones, J . (2012). “The Egyptian Blogosphere: A CounterNarrative of the Revolution." Proceedings of the ACM 2012 conference on Computer Supported Cooperative Work, Seattle, WA, 17-26.

Amabile, T. M., Goldfarb, P., \& Brackfield, S. C. (1990). "Social influences on creativity: evaluation, coaction, and surveillance." Creativity Research J ournal, 3(1): 6-21.

Barclay, D., Higgins, C. \&Thompson, R. (1995). "The Partial Least Squares Approach to Causal Modeling, Personal Computing Adoption and Use as an Illustration," Technology Studies, 2(2): 285-309.

Benevenuto, F., Rodrigues, T., Cha, M., \& Almeida, V. (2009). "Characterizing User Behavior in Online Social Networks," Proceedings of the 9th ACM SIGCOMM conference on Internet measurement, pp. 49-62.

Bhattacherjee, A. (2002). "Individual Trust in Online Firms: Scale Development and Initial Test," J ournal of Management Information Systems, 19(1): 211- 241.

Boyd, D. M., \& Ellison, N. B. (2008). "Social Network Sites: Definition, History, and Scholarship."J ournal of Computer-Mediated Communication, 13(1): 210-230.

Boyle, M., Schmierbach, M., Armstrong, C., \& McLeod, D. (2004). "Information seeking and emotional reactions to the September 11 terrorist attacks." Journalism and Mass Communication Quarterly, 81(1): 155-167. 
Buss, A. H. (1980). Self-consciousness and social anxiety. San Francisco: Freeman.

Chen, R., Sharman, R., Rao, H. R., \& Upadhyaya, S. (2007). “Design principles for critical incident response systems." Information Systems and e-Business Management, 5(3): 201-227.

Chin, W. W. (2010). "How to Write Up and Report PLS Analyses," in Vinzi, V. E., Chin, W. W., Henseler, J., and Wang, H. (Eds.), Handbook of Partial Least Squares: Concepts, Methods and Applications, Springer Verlag, New York, NY, pp. 655-690.

Cohen, N., \& Arieli, T. (2011). "Field research in conflict environments: Methodological challenges and snowball sampling." J ournal of Peace Research, 48(4): 423-435.

Fritz, C. E. (1961). “Disaster,” in Merton, R.K. and Nisbet, R.A. (Eds.), Contemporary social problems, Harcourt, Brace \& World, New York, NY, pp. 651-694.

Gagne, M. \& Deci, E. L. (2005). “Self-determination theory and work motivation.” J ournal of Organizational Behavior, 26(4): 331-362.

Gefen, D., Rigdon, E. E., \&Straub, D. (2011). “An Update and Extension to SEM Guidelines for Administrative and Social Science Research.” MIS Quarterly, 35(2): iii-xiv.

Gefen, D., \& Straub, D. (2005). "A practical guide to factorial validity using pls-graph: Tutorial and annotated example." Communications of the Association for Information Systems, 16: 91-109.

Gefen, D., Straub, D., \& Boudreau, M. (2000). "Structural Equation Modeling and Regression: Guidelines for Research Practice." Communications of the Association for Information Systems, 4: 1-77.

Geisser, S. (1975). “The predictive sample reuse method with applications." J ournal of the American Statistical Association, 70(350): 320- 328.

Govern, J . M., \& Marsch, L. A. (2001). “Development and validation of the situational selfawareness scale." Consciousness and Cognition, 10(3): 366- 378.

Hagar, C., \& Haythornthwaite, C. (2005). "Crisis, farming and community.” J ournal of Community Informatics, 1(3): 41-52.

Ke, W., \& Zhang, P. (2010). "The Effects of Extrinsic Motivations and Satisfaction in Open Source Software Development," J ournal of the Association for Information Systems, 11(12): 784-808.

Koestner, R., \& Zuckerman, M. (1994). “Causality orientations, failure, and achievement.” J ournal of Personality, 62(3): 321-346.

Lindell, M. K., \& Whitney, D. J . (2001). "Accounting for Common Method Variance in CrossSectional Research Designs." J ournal of Applied Psychology, 86(1): 114-121.

Mayer, R. C., Davis, J. H., \& Schoorman, F. D. (1995). “An integrative model of organizational trust," Academy of Management Review, 20(3): 709-734.

Mayfield, A. (2006). "What Is Social Media?" Spannerworks.

McGraw, K. O. (1978). "The detrimental effects of reward on performance: A literature review and a prediction model." In Lepper, M. R. and Greene, D. (Eds.), The Hidden Costs of Reward, Erlbaum, Hillsdale, NJ, pp. 33-60.

McGraw, K. O., \& McCullers, J. C. (1979). "Evidence of a detrimental effect of extrinsic incentives on breaking a mental set." J ournal of Experimental Social Psychology, 15(3): 285-294.

McKnight, D. H., \& Chervany, N. L. (2001) "What trust means in e-commerce customer relationships: An interdisciplinary conceptual typology." International J ournal of Electronic Commerce, 6(2): 35- 39. 
McKnight, D. H., Choudhury, V., \& Kacmar, C. (2002). "Developing and Validating Trust Measures for E-Commerce: An Integrative Typology," Information Systems Research, 13(3): 334-359.

Mitroff, I. I. (2004). Crisis leadership: Planning for the unthinkable. John Wiley \& Sons, Hoboken, NJ .

Moore, G. C., \&Benbasat, I. (1991)."Development of an Instrument to Measure the Perceptions of Adopting an Information Technology Innovation," Information Systems Research, 2(3): 192-222.

Oh, O., Agrawal, M., \& Rao, H. R. (2013). “Community Intelligence and Social Media Services: A Rumor Theoretic Analysis of Tweets During Social Crises.” MIS Quarterly, 37(2): 407426.

Palen, L., Hiltz, S. R., \&Liu, S. B. (2007). “Online Forums Supporting Grassroots Participation in Emergency Preparedness and Response." Communications of the ACM, 50(3): 54-58.

Palen, L., Vieweg, S., Liu, S. B., \&Hughes, A. L. (2009). "Crisis in a Networked World Features of Computer-Mediated Communication in the April 16, 2007, Virginia Tech Event." Social Science Computer Review, 27(5): 1-14.

Pan, S. L., Pan, G., \& Leidner, D. E. (2012). “Crisis Response Information Networks.” J ournal of the Association for Information Systems, 13(1): 31-56.

Pang, N., \&Ng, J . (In Press). “Twittering the LittleIndia Riot: Audience responses, information behavior and the use of emotive uses". Computers in Human Behavior.

Park, N., Kee, K. F., \& Valenzuela, S. (2009). "Being Immersed in Social Networking Environment: Facebook Groups, Users and Gratifications, and Social Outcomes." CyberPsychology \& Behavior, 12(6): 729-733.

Podsakoff, P. M., MacKenzie, S., \& Lee, J . (2003). “Common Method Biases in Behavioral Research: A Critical Review of the Literature and Recommended Remedies." J ournal of Applied Psychology, 88(5): 879-903.

Procopio, C. H., \& Procopio, S. T. (2007). "Do you know what it means to miss New Orleans? Internet communication, geographic community, and social capital in crisis." J ournal of Applied Communication Research, 35(1): 67-87.

Raacke, J., \& Bonds-Raacke, J . (2008). "MySpace and Facebook: Applying the Uses and Gratifications Theory to Exploring Friend-Networking Sites." CyberPsychology \& Behavior, 11(2): 169-174.

Reinholt, M., Pedersen, T., \&Foss, N. J . (2011). "Why a Central Network Position isn't Enough: The Role of Motivation and Ability for Knowledge Sharing in Employee Networks." Academy of Management J ournal, 54(6): 1277-1297.

Ringle, C. M., Wende, S., \& Will, S. (2005). SmartPLS 2.0 (M3) Beta, Hamburg, http:// www.smartpls.de.

Ryan, R. M., \&Deci, E. L. (2000). "Self-Determination Theory and the Facilitation of Intrinsic Motivation, Social Development, and Well-Being." American Psychologist, 55(1): 68- 78.

Sarcevic, A., Palen, L., White, J ., Starbird, K., Bagdouri, M., \&Anderson, K. (2012). “'Beacons of Hope' in Decentralized Coordination: Learning from On-the-Ground Medical Twitterers During the 2010 Haiti Earthquake 2012", Proceedings of 2012 ACM Conference on Computer Supported Cooperative Work, Seattle, WA.

Schultz, F., Utz, S., \& Göritz, A. (2011). "Is the Medium the Message? Perceptions of and Reactions to Crisis Communication via Twitter, Blogs and Traditional Media," Public Relations Review, 37(1): 20-27. 
Semaan, B., \& Mark, G. (2011). "Technology-Mediated Social Arrangements to Resolve Breakdowns in Infrastructure During Ongoing Disruption." ACM Transactions on Computer-Human Interaction, 18(4): 1-21.

Shklovski, I., Burke, M., Kiesler, S., \& Kraut, R. (2010). "Technology Adoption and Us in the Aftermath of Hurricane Katrina in New Orleans." American Behavioral Scientist, 53(8): 1128-1246.

Shklovski, I., Palen, L., \& Sutton, J . (2008). "Finding community through information and communication technology during disaster events." Proceedings of 2008 ACM Conference on Computer Supported Cooperative Work, San Diego, Vancouver, BC, Canada, pp. 127-136.

Spence, P. R., Lachlan, K. A., Lin, X., \& del Greco, M. (2015). “Variability in Twitter Content Across the Stages of a Natural Disaster: Implications for Crisis Communication." Communication Quarterly, 63(2): 171-186.

Spence, P. R., Westerman, D., Skalski, P., Seeger, M., Sellnow, T., \& Ulmer, R. R. (2006). "Gender and age effects on information seeking after 9/11." Communication Research Reports, 23(3): 217-223.

Starbird, K., \& Palen, L. (2012). “(How) Will the Revolution be Retweeted? Information Diffusion and the 2011 Egyptian Uprising." Proceedings of the ACM 2012 conference on Computer Supported Cooperative Work, pp. 7-16.

Stone, M. (1974). “Cross-validatory choice and assessment of statistical predictions.” J ournal of the Royal Statistical Society: Series B, 36(2): 111- 147.

Taylor, S., \& Todd, P. A. (1995)."Understanding Information Technology Usage: A Test of Competing Models," Information Systems Research, 6(4): 144-176.

Taylor, M., Wells, G., Howell, G., \& Raphael, B. (2012). "The Role of Social Media as Psychological First Aid as a Support to Community Resilience Building." The Australian J ournal of Emergency Management, 27(1) 20-26.

Thompson, R. L., Higgins, C. A., \& Howell, J. M. (1991). "Personal Computing: Toward a Conceptual Model of Utilization," MIS Quarterly, 15(1): 124-143.

Valdez, A., \& Kaplan, C. D. (1999). "Reducing selection bias in the use of focus groups to investigate hidden populations: The case of Mexican-American gang members from South Texas.” Drugs and Society, 14(1-2): 209-224.

Vansteenkiste, M., Simons, J., Lens, W., Sheldon, K. M., \& Deci, E.L. (2004). "Motivating learning, performance, and persistence: The synergistic effects of intrinsic goal contents and autonomy-supportive contexts." J ournal of Personality and Social Psychology, 87 (2): 246-260.

Venkatesh, V., \& Davis, F. D. (2000). "A Theoretical Extension of the Technology Acceptance Model: Four Longitudinal Field Studies," Management Science, 45(2): 186-204.

Venkatesh, V., Morris, M., Davis, G.B., \&Davis, F. D. (2003). “User Acceptance of Information Technology: Toward a Unified View.” MIS Quarterly, 27(3): 425-478.

Vieweg, S., Palen, L., Liu, S., Hughes, A. \&Sutton, J . (2008). “Collectiveintelligence in disaster: Examination of the phenomenon in the aftermath of the 2007 Virginia Tech Shootings." Proceedings of the 5th International ISCRAM Conference. Washington, DC, U.S., pp. 44-54.

Wang, X. (2014). “How Do People Participate in Social Network Sites after Crises? A SelfDetermination Perspective." Social Science Computer Review, 32(5): 662-677.

Wang, X., \&Clay, P. F. (2012). “Beyond Adoption Intention: Online Communities and Member Motivation to Contribute Longitudinally." J ournal of Organizational Computing and Electronic Commerce, 22(3): 215-236. 
Wang, X., Clay, P. F., \& Forsgren, N. (2015)."Encouraging knowledge contribution in IT support: social context and the differential effects of motivation type", Journal of Knowledge Management, 19(2): 315 - 333

Wang, X., \& Li, Y. (2014). "Trust, Psychological Need, and Motivation to Produce User Generated Content: A Self-Determination Perspective."J ournal of Electronic Commerce Research, 15(3): 241-253.

Wang, X., \& Li, Y. (In Press). "Understanding collaborative resilience from continuous disruption: an actor-network perspective." Behaviour \& Information Technology.

Warshaw, P. R. (1980). "A new model for predicting behavioral intentions: An alternative to Fishbein." J ournal of Marketing Research, 17(2): 153-172.

Yanay, U., Benjamin, S., \&Yamin, H. G. (2011). "Networking emergency teams in J erusalem.” Disaster, 35(1): 183-199. 


\section{Appendix: Instrument ${ }^{5}$}

Social Influence (Moore and Benbasat, 1991; Taylor and Todd, 1995):

SI1 SI1: People who influence my behaviour think that I should use _.

SI2 SI2: People who are important to me think that I should use .

SI3 SI3: Using is a status symbol for people in my peer group.

SI4 SI4: People in my peer group who use _ can thereby improve their image.

Trust (Benevolence) (McKnight et al., 2002):

TB1 I believe that people in would act in my best interest.

TB2 If I required help, people in _ would do their best to help me.

TB3 People in are interested in my well-being, not just their own.

TB4 People in _ are open and receptive to my needs.

Trust (Integrity) (McKnight et al., 2002):

TI1 People in _ are truthful in their dealings with me.

TI2 I would characterize people in _ as honest.

TI3 People in _ would keep their commitments.

TI4 People in _ are sincere and genuine.

Controlled Motivation (Ke and Zhang, 2010):

CM1 I am strongly motivated by various kinds of bonus (e.g., credit and rank) I can earn through my participation in .

CM2 I am keenly aware of the possible help for my life and work that may be brought by my participation in .

CM3 I am strongly motivated by the recognition I can earn from other people in _.

\section{Autonomous Motivation (Ke and Zhang, 2010):}

AM1 I have a strong positive feeling toward .

AM2 The reason I participate in _ is because of the way that people interact with each other.

AM3 My attachment to this group is primarily based on similarity of my desired interaction pattern and those represented by _.

Browse Content in SNSs (Ke and Zhang, 2010):

VSNS1 I devoted a large number of hours to browse information about MH370 in . VSNS2 I devoted a lot of effort to browse information about MH370 in _.

Share Content in SNSs (Ke and Zhang, 2010):

FSNS1 I devoted a large number of hours to share information about MH370 in _.

FSNS2 I devoted a lot of effort to share information about MH370 in _.

\section{Comment in SNSs (Ke and Zhang, 2010):}

CSNS1 I devoted a large number of hours to comment on the information about MH370 in _. CSNS2 I devoted a lot of effort to comment on the information about MH370 in .

\section{Situational Self-Awareness (Govern and Marsch, 2001):}

SA1 Right now, I am keenly aware of everything about MH370.

SA2 Right now, I am conscious of what is going on about MH370.

SA3 Right now, I am conscious of all objects about MH370.

\footnotetext{
5 The instrument was first written in English and was then translated into Chinese by two bilingual Chinese research assistants (RA). The first RA translated the instrument into Chinese; the second RA translated the instrument back to English. Any differences or inconsistencies were discussed and resolved.
} 
Copyright: (C) 2016 Wang. This is an open-access article distributed under the terms of the Creative Commons Attribution-NonCommercial 3.0 Australia License, which permits noncommercial use, distribution, and reproduction in any medium, provided the original author and AJ IS are credited.

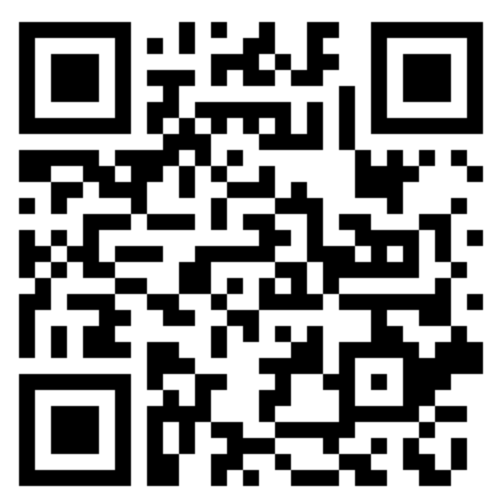

